\title{
A MECHANISM OF LEXICAL BORROWING
}

\section{Celeste M. Sullivan}

\author{
Brown University, Providence, R.I.
}

\begin{abstract}
This paper offers a model to explain the general observation that lexical items are more often borrowed from a higher status language into a lower status one, than visa versa. Material from Lahore, Pakistan, shows that in casual speech among plurilinguals codeswitching is the norm. In formal contexts, in which there is attention to proper language, educated speakers filter out features which are not part of the standard language. Constraints on language and education in the hierarchical social structure withhold from most speakers of the lower status languages the knowledge necessary to evaluate their own speech in this way, thus allowing features of other languages to become established in their language. ${ }^{1}$
\end{abstract}

\section{Introduction}

This paper addresses the question of why, in many situations of language contact, lexical items are more frequently borrowed from the higher status language to the lower status one, than they are from the lower to the higher. This asymmetric pattern of borrowing is quite common (Mougeon \& Beniak, 1991:199-200), which has led some linguists to assert that it is the rule (see discussion in Thomason \& Kaufman, 1988:43-44). The explanation proposed here is based on synchronic observations in a multilingual community, but the question it addresses is not one that concerns synchronic language but rather this particular aspect of diachronic change. The phenomena that will be discussed in this paper resemble the well-analysed phenomenon of code-switching, however differ from it in certain respects, in particular with regard to the lack of conscious agency. We will see that the mechanism of borrowing described is the result of a combination of language practices in the community, without deliberate intent. As will be addressed in more detail below, language input and the process of reanalysis by the new generation of speakers of the recipient language is

\footnotetext{
${ }^{1}$ I would like to thank the many people of Lahore, all of whom welcomed me and helped in countless ways with my work, in particular, Aurangzeb Alamgir and the Urdu Department at Punjab University, Atif Tufail and Shazia Atif, Hamid Akbar, Shahab ud-Din and Tazeen Shahab, Arfa Zehra, Shahid Saddiqi, Shafiq and Iqbal Suraj-Din and Shamim Iqbal. I would also like to thank Carol Myers-Scotton for extensive comments on an early version of this paper, Henning Schreiber and an anonymous reviewer for their comments, Joseph Salmons, and William O. Beeman for his tireless support of my work. Errors or irregularities of this paper are my own responsibility.
} 
crucial. The mechanism described here is only one of several that contribute to borrowing. As members of the community take new cultural and technological elements into their lives, the words for these elements will become a common and necessary part of the lexicon. Words such as "career" and "practice" in the language of the professionals below reflect different organization of, and attitudes towards, work associated with a new culture. Beyond this, however, perfectly serviceable words are also replaced by near equivalent words in a dominant language. This paper focuses on one mechanism behind this process.

The process by which this occurs involves social conditions typically found in a firmly stratified social environment and some very widespread features of language and language use. The most important factors that play a role in lexical borrowing in Lahore are:

1 - the effects of the important distinction between formal and informal speech contexts and the effects of the great difference with regard to speech conventions in these contrasting contexts;

2 - the limited access to education and the resultant differing modes of control of language;

3 - the neurological processes involved in recalling lexical items.

The analysis presented here pulls together a wide range of data gathered over a period of two years. In tracing the path of lexical items from one language to another it has been necessary to include many kinds of material and to go beyond the specifics of the separate observations to a model of the interaction of several distinct phenomena characteristic of the community. Some of the important material for this analysis was recorded in interviews, but the tape recorder could only be used for certain contexts. Candid observations of conversations, and of norms of speech and interaction in informal and formal contexts, observations of the effects of contrasts in living conditions, education, and other factors, were as important to the analysis presented here, as were field recordings.

\section{The Setting of the Study}

The field work for this study was done in Lahore, Pakistan. Lahore is situated in the heart of the Punjab, and is a centre of Punjabi and Urdu culture. Lahore was already an established settlement in 1005, when Mahmud of Ghazna built a mosque there as he was passing through and assigned the now famous sufi, Data Ganj Baksh, to maintain it. It is a multilingual community, and I was able to observe a wide range of multilingual phenomena. In Lahore you have English, Urdu, Punjabi, Arabic, and some Pashto. Each of these languages is identified with certain domains within the community (Rahman, 2001, 2002; Mansoor, 1993). Arabic is used mainly for ritual purposes, English is the official language associated with international commerce and the elite who control the government and the economy, Urdu is the national language and serves as a lingua franca throughout Pakistan. Although, as a lingua franca, it had not been unknown, Urdu was brought by the British when they annexed the Punjab in 1849. It was in the interests of economic efficiency, to allow them to simply extend the middle and lower levels of their existing administrative apparatus to their new territory, that the British decided that Urdu was the appropriate language of administration in the Punjab. The objective expressed by the British, of establishing a class of Urdu speaking elite, can be seen in its fulfilment today. They were, however, not accurate in their assessment of Punjabi, which they declared to be a dying (Mir, 2002:43; or specious-Cust, 1878:38) language. ${ }^{2}$ Punjabi is the local language and the language of the home for a majority in Lahore, despite the many people who have switched to Urdu. ${ }^{3}$ Punjabi is also usually the only language spoken by those with little or no education, who in the Punjab are many. It is a very vital

\footnotetext{
${ }^{2}$ Leitner (1882) gives an evaluation of the language and educational situation in the Punjab after annexation.

${ }^{3}$ Contemporary language use reflects the categories described by Mitchell (2006).
} 
language and notorious for its variability, among other things. Traces of Persian are evident in Urdu, Punjabi (and Pashto). English was also brought in by the British with annexation, but at that time it was taught only to the sons of the most powerful chiefs who had become their allies (hence the name "Chief's College" by which these schools were first known and which is still used locally to refer to Aitchison College, one of the institutions set up by the British for that purpose). Today its use is not quite as exclusive, but access to English education is restricted by its very high cost, in conjunction with the enormous economic divide that exists in Pakistan. For the majority of the population Urdu and English are learned as second languages. Thus, they require deliberate educational effort either in school or from parents who are educated and speak to their children in one of these languages, much like in cases of diglossia. Especially for the large numbers of uneducated or undereducated working people Urdu is limited and English is barely known. ${ }^{4}$

Punjabi and Urdu belong to the Sanskritic branch of the Indo-European language family, distant from the Germanic branch, to which English, the politically dominant language, belongs. Punjabi evolved within the geographical confines of the Punjab, while Urdu evolved in a number of locations across South Asia (for the history of Urdu see Faruqi, 2001). At present, the grammatical structures of Punjabi and Urdu are so close in Lahore that they are considered to be identical. In this community, in which Punjabi has been the main language for centuries, the differences that exist between the syntax of Punjabi and Urdu are converging for many speakers. Bilingual speakers describe the distinction in terms of the lexicon and morphological lexemes and affixes for each of these languages. Every language also has a distinctive set of intonation features and parameters for syllable and word structures. There are many cognates between Punjabi and Urdu. There are Urdu speakers, from Karachi more than Lahore, who will tell you that Punjabi is merely a deterioration of Urdu, but each has an independent history which can be traced back to distinct regional languages in Middle Indo-Aryan (Kohli, 1992:52-53 for Urdu; 58-59 for Punjabi). Punjabi and Urdu are verbfinal and highly analytic. In the higher registers of Urdu most verbal constructions are composed of a stem, a participle, or some other nominal form, imbedded in a structure involving two or three auxiliary verbs. In Punjabi and the simpler registers of Urdu finite main verbs or constructions with fewer auxiliaries are more common. In both languages adjectives usually precede their noun. Arabic is radically different in structure from the other, Indo-European languages spoken in Lahore. Many of the nouns in everyday use and many of the nominal forms around which the verbal forms are built come from Arabic, in many cases via Persian. Lengthy utterances of correct classical Arabic are heard several times a day in religious contexts, and written Arabic is visible in ornamental calligraphy. The longer examples are not entirely understood by most of the community, but most people do know the meaning of the Arabic expressions used for greetings and in conversation.

As is the case for many languages in the Islamic world, a variant of the Arabic script, in this case Nastaliq (from Persian) is the script used to write Urdu and Punjabi. Arabic is written in Naskh. Naskh is written straight across the line whereas Nastaliq is written in clusters of letters which flow on a diagonal. In books written in both Arabic and Urdu, the contrast of these two styles is evident at a glance. English is written in Roman script. As a high status language, English appears in ornamental contexts, such as "Welcome" across the door of a public transportation wagon, and Roman script is sometimes used in ornamental contexts for words from Urdu. This use of Roman script seems to be increasing: in casual inspections, in 2000 most Eid cards were written in Nastaliq, but in 2002 most were written in Roman script, in Urdu, Arabic, and English. Young Lahoris are also using Roman script routinely to write casual Urdu and Punjabi in internet chats. Programs exist for the Nastaliq script but in 2002 they required special installation.

While Punjabis are proud to be Punjabis, ethnic identity is not generally a strong motivation. In other parts of Pakistan there has been agitation with regard to language rights, but Punjabis have

${ }^{4}$ Readers are referred to Qadeer (1983) for a socio-economic description of Lahore. 
been content with a lack of official attention towards their language. In the national political sphere Punjabis are clearly the most powerful group and the national majority. English and Urdu are the official and national languages wielded effectively by powerful educated Punjabis. ${ }^{5}$

\section{Involuntary switches}

Some communities are more tolerant of codeswitching than others and in many contexts in Lahore codeswitching is well tolerated. Eavesdropping in situations such as in a bus or a waiting room, or if the phone rang while I was in an office, I heard people switching extensively in their casual conversations. For speakers with competence in more than one language, codeswitching is more natural than to stick to one of them. This has been noted elsewhere (for example Weinreich, 1968; Lambert, 1969; Perecman, 1989; Gardner-Chloros, 1995). Speaking for the tape recorder is different from casual conversation, however, as speakers adjust to their audience, identify a language in which to be interviewed, and then try to stick to it. Language switching in the recorded examples is very different from what can be heard as one goes about unnoticed. In spite of a conscious intention to speak in Urdu, the "middle status" language, for the recording, speakers frequently switch, contrary to their intention, to English. In the examples below, having lapsed unaware, speakers can be seen to stop in "mid switch" and return to the language in which the interview was to be given.

Work on borrowing and codeswitching has exhaustively analysed the structures found in codeswitching by plurilinguals having competence in the source language. What has not been explained is how these structures (lexical items, in particular) go from codeswitching by these plurilinguals to the speech of persons having no competence in the source language. Studies of codeswitching attribute motivations to social meanings associated with the available languages (for example, Myers-Scotton, 1993; LePage \& Tabouret-Keller, 1985). These studies show how speakers manipulate shared knowledge of two or more languages in order to include a range of social meanings that are not available in a single language. Hours of eavesdropping on unwary bilingual speakers and tape recordings of bilinguals' self conscious speech suggest that speakers frequently switch between languages intrasententially without social motivations. This can be attributed to at least two phenomena, others possibly await description:

\subsection{Switching by habit}

One important factor that appears to be at work in the speech of multilingual speakers in Lahore is related to the phenomenon of lexical attrition. This has been studied in other communities which have relocated and ceased to speak their original language for several years. It has been discovered that in these populations speakers frequently have difficulties in remembering words from their first language. What is frequently observed in Lahore is that people first produce the word that they use most often for something, often from the language that is used conventionally in the context in which that object appears. ${ }^{6}$

Bilingual speakers of English and Urdu giving an interview specifically intended to be an example of educated Urdu show the effects of the readier availability of the English lexicon with regard to certain topics:

\footnotetext{
${ }^{5}$ Muhajjirs, Urdu speaking migrants from India, are also a large and influential group in national politics and economics. The reader is referred to the work of Tariq Rahman for a detailed analysis of the politics of language in Pakistan.

${ }^{6}$ Mägiste (1979) documents longer recall times for lexical items in multilingual speakers, which also may be related to observations of lexical recall in the present paper.
} 
A veterinarian describing his work:

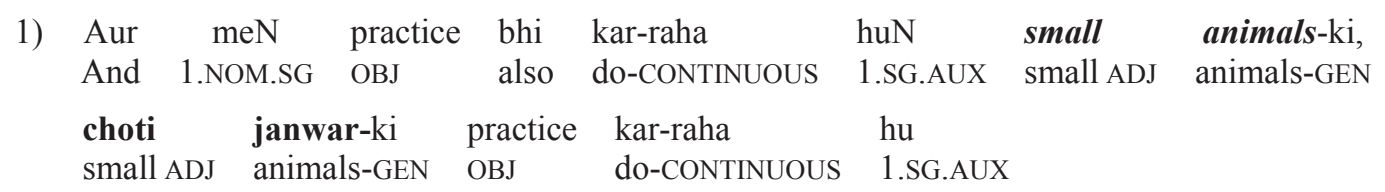

"And I am also operating a small animals practice, I am operating a small animals practice."

On the proper care of pets:

2) Hhurriah sahih time-ke daengi aap-ko side-keliye le-jaenge, aap-ko

Freedom-OBJ proper-ADJ time-GEN give-FUT 3.PL.DAT side-DAT bring-FUT 3.PL.DAT

$\begin{array}{llllllll}\text { exerci- } & \text { warzish } & \text { daengi } & \text { aap-ko } & \text { mukamel } & \text { unki } & \text { care } & \text { karengi. } \\ \text { exerci-OBJ } & \text { exercise-OBJ } & \text { give-3.PL.FUT } & \text { 3.PL.DAT } & \text { complete-ADJ } & \text { 3.SG.GEN } & \text { care-OBJ } & \text { do-3.PL.FUT }\end{array}$

"You must give them adequate free time [time to run] you must take them by your side [for walks], you must give them exerci-exercise, you must give them complete care."

An executive speaks of his habits of language use:

3) dost-ko invitation bej-raha huN - -ko dawatnama bej-raha huN friend-DAT invitation-OBJ send-CONTIN. 1.SG.AUX —DAT invitation-OBJ send-CONTIN. 1.SG.AUX

“... [If I am] sending an invitation to a friend, sending an invitation.”

And of the early years of his career:

4) MeN-ne armament branch-meN commission liya $\mathrm{t}^{\mathrm{h}} \mathrm{a}, \quad$ lekin

1.SG.INS armament-ADJ branch-LOC commission-ERG take-PST.PTCP 3.SG.AUX but

ba'd-meN meN-ne change-kar ke tabdīl-kar ke

later-ADV 1.SG.INS change-ERG make-PST.PTCP change-ERG make-PST.PTCP

"I took a commission in the armament branch, but after a while I changed (I changed)."

5) (What advice do you have for those who would like to be successful, as you are?)

Well, there's ... no substitute for hard work and honesty. Jab bhi imandari aur mehnet aur lagan se kam karenge ap uska inam milega, reward zurur milega aur ye ek wahid tariqa he ap ko zindagi kamyab hone ka koi dusra short cut ap ko, insan ko taaqi ke lie dusra short cut us ki saih manzəl pe nahĩ pəhonch sakta,

Well there's ... no substitute for hard work and honesty. Whenever one works diligently and faithfully and with commitment they will earn success, they will certainly obtain (their) reward. This is the only way to success in life; there's no short cut, there no other way to achieve a sound outcome,

sewai ek achhe mehnti career-ke-through

other than INDF.DET good-ADJ diligent-ADJ career-(GEN).INS

"other than through a good diligent career." 8

(Note: the GEN suffix would link an Urdu noun meaning "by means of".)

As pointed out by Weinreich (1968:77-78), when distracted from attention to language by subject matter of an emotional content, speakers are likely to switch without realizing it. The

${ }^{7}$ 3.PL "aap" is used as the polite form of $2 \mathrm{SG}$.

${ }^{8}$ The executive who provided this sample spoke very refined English with no intrusions from any other language. 
veterinarian above, who runs a completely sanitary, modern clinic which offers services for the pets of residents in the upscale parts of the city, betrays his dissatisfaction with the problem of stray dogs:

6) (Pakistani hukumat ka program he pehle to cantonments me shero me)

(There are Pakistani government programs first in the cantonments and the cities)

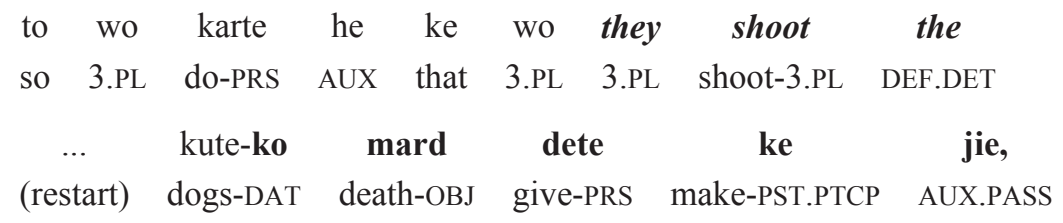

"what they do is they shoot the ...the dogs are killed,

unwanted dogs un-ke hume zurrurat nahi he

unwanted-ADJ dog-PL 3.PL.GEN 1.PL.DAT necessity-SBJ NEG 3.PL.AUX

unwanted dogs, for which we have no need,

$\begin{array}{lcccccc}\text { un-ko } & \text { mard } & \text { de } & \text { lekin } & \text { phir bhi } & \text { is-ko } & \text { hundred percent } \\ \text { 3.PL.DIST.DAT } & \text { death-ERG } & \text { give-PST.PTCP } & \text { but } & \text { even so } & \text { 3.PL.PROX.DAT } & 100 \%\end{array}$

[They] kill them but even so this [isn't] 100\% [effective]."

When not speaking for the tape recorder, in their places of business, the speakers above switched frequently back and forth between English and Urdu (and in the case of the veterinarian, Punjabi). In these and similar businesses there are workers with much poorer education who at times are simply present but often participate in multilingual interactions with speakers such as these. In home contexts, servants in particular, as drivers, cooks and housecleaners, security guards, and peons, are present while fluent plurilinguals are at their recreation, a context in which extensive codeswitching is the norm.

\subsection{Switching out of euphony.}

The other phenomenon that can be frequently overheard in casual speech, but which was not as evident in the more self conscious context of the tape recording, involved switching to English as the primary (matrix) or single language of a phrase that included several words whose source language was English. For example, passengers in the better bus system could be overheard, in discussing personal matters, to switch to English in clauses including the names of institutions which were in English, even though the social connotation of what was being said was no different, was just as personal, as the rest of the conversation, which was in Urdu. The absence of English words being realised in the phonology of Urdu (or of Punjabi, which was so common in the wagons that travelled the routes in the lower income parts of the city) was noticeable in the speech of girls riding the bus between their schools and the neighbourhoods where the educated classes live. Each of the languages spoken in Lahore has its own distinct intonation patterns. ${ }^{9}$ In the city-wide repertoire of Lahore, to speak a word that had originated in English in a stream of speech in Urdu would distort the pronunciation of the word from English in fitting it to the rhythm and syllabification of Urdu. Speakers who are educated in English are aware that it is the source language of these words and show a strong preference to pronounce them according to English phonology (RP, if possible). Speakers clearly avoid distorting words for which they do know the

${ }^{9}$ Descriptions of some of these features can be found in Bahl (1957a, b); Bala (1994), Sharma (1971). There are also intonation features that are shared across languages. 
source language and are able to produce the pronunciation of the source language. ${ }^{10}$ Such distortion could be interpreted to suggest that the speaker was "uneducated", a stigmatised class. One motivation for codeswitching is to avoid a string of speech which would require repeated abrupt alternation between rhythmic patterns. ${ }^{11}$ Exceptions to this are words such as "time" "side" "television", which are thoroughly absorbed in to all registers of Urdu and have been so for over a generation.

\section{The Language of the Uneducated}

The patterns of codeswitching above are performed only by people who have some command of all languages involved. The observation under consideration here is the greater frequency with which words enter the lexicon of the lower status language, which is the primary language of people who specifically lack command of many languages, particularly the languages of education. So how do these words become a permanent part of the language of the people who don't know the source languages, and who themselves cannot codeswitch to these languages? It is exactly this inability that allows these words to become accepted as part of the language of the poorly educated.

In Lahore as in many communities there are formal and informal modes of speech. The more formal the context, the less acceptable codeswitching will be, especially intrasentential codeswitching. Speaking ability is prized; men and women who speak in public regularly learn to control their language, keeping to English, particularly (see below), but also Urdu, or Punjabi, as the case may be. In formal contexts the languages of education will be used, usually English, or Urdu (Punjabi only in a very limited number of contexts). ${ }^{12}$

In most interchanges between speakers of different repertoires, those speaking the languages of education will be in a position of superiority. Many speakers with little education however, spend an important part of their time in the presence of educated multilingual speakers who are their employers, customers, landlords, and so on. For the superior party in the exchange, speech events in these contexts do not typically command attention to correct speech. As noted above, it requires deliberate attention for most bilingual English-Urdu speakers to produce an utterance entirely in Urdu, without switching to English at all. To do so is unusual, even with effort. English words come out without being noticed, and the interaction moves on. Generally, a poorly educated interlocutor can glean enough information from context to comprehend the meaning they need from the interaction. These interactions are usually face-to-face, so there are objects or gestures to assist in comprehending. In such a context the meaning taken is often approximate and dependent upon the context in which the word is encountered. This could account for the shift in meaning that is so common in borrowings. These words from the higher status language are at first passively understood, but can then become part of the spoken vocabulary. The recipients of these words receive no training in the phonology of the source language, which accounts for the phonological reanalysis which usually takes place (such as described in Heath, 1989). Being unaware that there is anything different about these words, except perhaps, that they have been used by people of higher status and education, poorly educated speakers can use these words as one would any new word. Factors involved in processes of lexical retrieval, such as prior use, could actually favour these new words over others, for example in conversations on subjects regarding which these new, borrowed,

${ }^{10}$ This is especially true of a high status language like English. High status speakers, especially, but not only, girls, deny or conceal knowledge of low status language. Speakers without English education have no choice but to restructure words of English origin to Urdu phonology, it may be that avoidance of this is one of many ways that the educated distinguish themselves from the uneducated or less educated.

${ }^{11}$ Clyne (1980) documents similar shifting triggered by the occurrence of words, as he says, "at the intersection of two languages".

${ }^{12}$ In extremely formal, ritual contexts, Arabic is used, which is also a language of education, although education through a different set of institutions. 
words have recently been heard. This would fit with the observation that borrowings tend to be clustered in certain domains. Some speakers may associate prestige with these words, but prestige is a factor in deliberate word choice. What is important to note is that words are transferred from one language to another without the agents of this transfer being aware that this is what they are doing. Once these words are spoken outside the context in which they were first heard, in other contexts in the lives of these speakers with different participants, their utterances will be heard by others who would rarely enter the presence of English speakers themselves.

Once these words find their way into the monolingual environment new language learners (such as children and apprentices) will reanalyse them as words of their own mother tongue, as they learn it or learn the tools of their trade. This stage of transmission within the community of non-English speakers can be seen to parallel Labov's work on monolingual variation in Philadelphia, where variants are introduced into the local community by individuals with contacts outside it (Labov 2001, 385). Within the local community these forms may be subject to influences of the community such notions of prestige or stigma, such as those described by Labov (1972) and Milroy (1987). The focus of the present paper is to describe the process of transfer of lexical items from multilingual speakers of the source and recipient languages to the community of speakers of the recipient language, so it beyond the present scope to pursue in detail the spread of these words in that community, parallel to Labov's and Milroy's work. Such borrowings do however, make up a large part of the vocabulary of non-English speakers. Punjabi, like other underappreciated languages, is usually learned as the mother tongue or by experience, rather than by formal instruction. It is taught in some schools as an optional subject, but more importantly, the majority of its speakers are those members of the community who have the least education, if they are educated at all. These learners establish their competence on the mass of unselfconscious input of language in their environment. ${ }^{13}$ I often encountered people, teaching me Urdu or Punjabi, saying, for example, "television" is Urdu, "TV" is Punjabi; or "measure" is Urdu, "inchtape" is Punjabi. Such informants were initially confused by my suggestion that the words did not actually belong to these languages but rather to English. Interestingly, one such impromptu teacher, after some thought, explained to me that a word might exist in several languages.

The ubiquity of the loss of Punjabi lexicon in common speech can be seen in the following example, a young man who speaks everyday Punjabi with his friends in the neighbourhood, providing an example of Punjabi for my research:

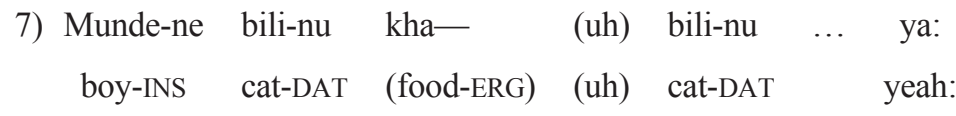

"The boy f-e ... the cat ... the cat ... yeah:

$\begin{array}{lcccc}\text { Munde-ne } & \text { bili-nu } & \text { khana } & \text { khway } & \text { e } \\ \text { boy-INS } & \text { cat-DAT } & \text { food-ERG } & \text { feed-PST.PTCP } & \text { AUX }\end{array}$

The boy has fed the cat food ...

$\begin{array}{llclcl}\text { khana } & \text { ek } & \text { Urdu-ka } & \text { lafez } & \text { hena } & \ldots \\ \text { food-CIT } & \text { SG.INDF } & \text { Urdu-GEN } & \text { word-NOM } & \text { TAG.Q } & \end{array}$

(but) "food" is an Urdu word, isn't it? . . .

${ }^{13}$ In the means of acquisition, the contrasting languages resemble a situation of diglossia. 


$\begin{array}{lcccll}\text { roti } & \text { ya } & \text { koi bhi } & \text { roti } & \text { khway } & \text { e } \\ \text { bread-ERG } & \text { or } & \text { any-ADJ } & \text { bread-ERG } & \text { feed-PST.PTCP } & \text { AUX }\end{array}$

has fed bread, or any kind of food."

(Note: "to feed", as "to eat", in Urdu and Punjabi must take a direct object, the thing which is to be eaten. In its narrow sense "roti" refers to flat wheat bread but is often used as a general reference to food.)

But "roti" is also an Urdu word, and for a short time it seems that the cat will not have been fed in Punjabi:

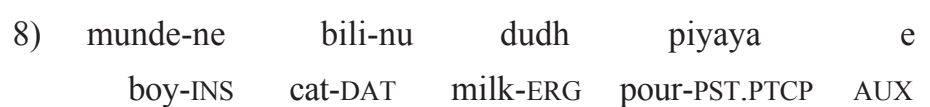

"The boy has given the cat milk to drink."

At last, something in Punjabi to feed the hungry cat:

9) munde-ne bili-nu ghosht kway e

boy-INS cat-DAT meat-ERG feed-PST.PTCP AUX

"The boy has fed the cat meat."

(Note: "ghosht" and "dudh" are cognate in Urdu and Punjabi, as is "bili").

This dilemma is widespread, and extends to otherwise educated speakers of these neglected languages; for example, an extremely well educated girl, fluent in English and enrolled in the best women's college:

8) (How would you say "you brought the wrong book?”)

“...again we'll borrow this word from Urdu: 'gulet' ... um 'gulet,' what would be 'wrong'?

'Thik nahīN,' again, that is Urdu, 'sahī,' that is also Urdu." (what would your grandmother use?) "Well, I don't know what she will use over here. Again I think I have to borrow word from Urdu language, and there are several words that we borrow from Urdu language."

This speaker's father spoke at length in English, Urdu, and Siraiki (which is usually treated as a dialect of Punjabi), with no problems whatsoever finding expressive words. The difference between father and daughter is an example of the change that has taken place in a generation.

\section{Prestige in Reverse: The Education of Prestigious Speakers Filters Out Features of Low Status Languages}

Why does this not occur in the higher status languages? The prestige of speaking a high status language like English is one of the most valuable commodities in the community. It is itself a sign of being a member of the elite. Correct English is pursued and studied intently. Competence in refined, faux-RP is only acquired through close and extensive contact with its speakers during the critical period of language acquisition (Johnson \& Newport, 1989). The most prestigious individuals speak pristine perfect English. To purge one's realization of a high-status language of features of a low status language has enormous social rewards. Apart from the prestige itself, rewards in social status translate into tangible rewards in jobs and promotion, and in marriage prospects. ${ }^{14}$ Knowledge of high status language is hoarded like any other precious commodity, effective education in the high registers of these languages is very expensive and actually cannot be had for money alone, but requires personal connections (see also Rahman, 2000, 2001, 2002). British English is studied and imitated, and is used ritually, for example to open formal meetings,

${ }^{14}$ Lahore is not unique in differential treatment on the basis of language, see Edwards (1979) and Scherer (1979). 
even if the meeting will continue in Urdu, or to greet an important client. Urdu is also taught in school and has a community of speakers who preserve knowledge of it for its aesthetic and emotional value, but overall attention to Urdu falls far short of that given to English. For some people knowledge of English is very similar to their knowledge of Arabic. It is learned in phraseand sentence-length formulae which do not permit alteration and so cannot be corrupted with words of another language. Education is heavily weighted towards well-off people and high status languages. Punjabi can be taken for a subject exam, as we might take French, but English and Urdu are the languages of instruction and of the examinations in general subjects, like history or science. There is a deliberate effort in education to maintain the standards of the high status languages, and individuals strive to perfect these languages because of the social and economic rewards which are associated with them.

There are contexts in which good Punjabi is valued, but they are considerably fewer and mostly to be found in private and home environments. A mother or grandmother will appreciate being spoken to in gentle and refined Punjabi, (this fits the observation that words for mother and so forth are often from lower status language) but she will also want her sons to succeed in business. The multitudes who lack education altogether or who have only minimal education are speakers of the low status Punjabi, for the most part they are denied the language education that would enable them to think critically about the words they commonly use, or would encourage them to standardise their day-to-day speech. Educated people will be able to identify and screen out words of Punjabi, even though they may deny knowledge of that stigmatised language.

\section{Conclusions}

The effect of these conditions over time is that, as lower status languages are not attended to much, words from other languages that may be used in utterances in those languages are not noticed and become incorporated into everyone's speech. There is a wide gap between writing in Punjabi and the majority of its speakers. With the passage of generations the knowledge of the earlier words passes away. Higher status languages are cultivated and preserved, because they have great rewards for those who can demonstrate knowledge of the correct form. The education of their speakers allows them to recognise and to block intrusions from lower status languages into the languages they pride themselves on. In the informal context codeswitching is the norm. In Lahore prestige leads to borrowing not so much because low status speakers take words from high status languages for their prestige, but because the prestige of the higher status languages motivates their speakers to purify them from the mixing which takes place everywhere in informal contexts.

\section{References}

Ammerlaan, Tom. 1996. "You Get a Bit Wobbly...": Exploring Bilingual Lexical Retrieval Processes in the Context of First Language Attrition. Ph.D. Dissertation, University of Nijmegen.

Bala, Madhu. 1994. "Declusterization in Punjabi: A socio- and psycho- linguistic perspective" Indian Linguistics 55:133-139.

Bahl, Kalicharan. 1957a. “Tones in Punjabi.” Indian Linguistics 17:139-147.

Bahl, Kalicharan. 1957b. "A Note on Tones in Western Punjabi (Lahanda)." Indian Linguistics 18:30-34.

Clyne, Michael. 1980. “Triggering and Language Processing.” Canadian Journal of Psychology 34.4:400-406. 
Cust, Robert N. 1878. A Sketch of the Modern Languages of the East Indies. London: Trübner \& Co., Ludgate Hill.

de Bot, Kees \& Robert Schreuder. 1993. "Word Production and the Bilingual Lexicon." In The Bilingual Lexicon. Robert Schreuder \& Bert Weltens (eds.) 191-214. Philadelphia: John Benjamins.

deGroot, Annette M.B. 1993. "Word-Type Effects in Bilingual Processing Tasks: Support for a mixed-representational system." In The Bilingual Lexicon. Robert Schreuder \& Bert Weltens (eds.) 27-51. Philadelphia: John Benjamins.

Edwards, John, R. 1979. "Judgments and Confidence Reactions to Disadvantaged Speech." In Language and Social Psychology. Howard Giles \& Robert N. St. Clair (eds.) 22-44. Baltimore: University Park Press.

Faruqi, Shamsur Rahman. 2001. Early Urdu literary Culture and History. New Delhi: Oxford University Press.

Gardner-Chloros, Penelope. 1995. "Code-switching in Community, Regional and National Repertoires: the Myth of the Discreteness of Linguistic Systems." In One Speaker, Two Languages: Cross-disciplinary perspectives on code-switching. Lesley Milroy \& Pieter Muysken (eds.) 68-89. New York: Cambridge University Press.

Heath, Jeffrey. 1989. From Code-Switching to Borrowing: Foreign and diglossic mixing in Moroccan Arabic. New York: Kegan Paul.

Johnson, Jacqueline \& Elissa L. Newport. 1989. "Critical Period Effects in Second Language Learning: The Influence of Maturational State on the Acquisition of English as a Second Language." Cognitive Psychology 21:60-99.

Kirsner, Kim, Erin Lalor \& Kathryn Hird. 1993. "The Bilingual Lexicon: Exercise, Meaning and Morphology.” In The Bilingual Lexicon. Robert Schreuder \& Bert Weltens (eds.) 213-248. Philadelphia: John Benjamins.

Kohli, Surindar Singh. 1992. Guru Granth Sahib: An analytical study. Amritsar: Singh Brothers.

Labov, William. 1972. "The Linguistic Consequences of Being a Lame." In Language in the Inner City: Studies in Black English. William Labov (ed.) 255-292. Philadelphia: University of Pennsylvania Press.

Labov, William. 2001. Principles of Linguistic Change, volume 2: Social Factors. Malden: Blackwell Publishers.

Lambert, Wallace E. 1969. "Psychological Studies of the Interdependencies of the Bilingual's Two Languages." In Substance and Structure of Language, Jaan Puhvel (ed.) Berkeley and Los Angeles: University of California Press.

Leitner, Gottlieb Wilhelm. 1882. History of Indigenous Education in the Punjab since Annexation and in 1882. Calcutta: Superintendent of Government Printing.

Mägiste, Edith. 1979. The competing language systems of the multilingual: A developmental study of decoding and encoding processes. Journal of Verbal Learning and Verbal Behavior 18:79-89.

Mansoor, Sabiha, 1993. Punjabi, Urdu, English, in Pakistan. Lahore: Vanguard.

Milroy, Lesley \& James Milroy. 1987. Language and Social Networks. $2^{\text {nd }}$ ed., Oxford: Basil Blackwell. 
Mir, Farina. 2002. The Social Space of Language: Punjabi Popular Narrative in Colonial India 1850 -1900. Ph.D. dissertation, Columbia University.

Mitchell, Lisa, 2006. "Making the Local Foreign: Shared Language and History in Southern India." Journal of Linguistic Anthropology 16.2:229-248.

Mougen, Raymond, and Edouard Beniak. 1991. Linguistic Consequences of Language Contact and Restriction. Oxford: Clarendeon Press.

Myers-Scotton, Carol. 2002. Contact Linguistics. Oxford: Oxford University Press.

Olshtain, Elite, \& Margaret Barzilay. 1991. "Lexical Retrieval Difficulties in Adult Language Attrition.” In First Language Attrition. Herbert W. Seliger \& Robert M. Vago (eds.) 139150. New York: Cambridge University Press.

Perecman, Ellen. 1989. "Language Processing in the Bilingual," in Bilingualism Across the Lifespan, Kenneth Hyltenstam \& Loraine K. Obler (eds.) New York: Cambridge University Press.

Qadeer, Mohammad A. 1983. Urban Development in the Third World: Internal dynamics of Lahore, Pakistan. New York: Praeger.

Rahman, Tariq. 2000. Unpleasant Essays: Education and Politics in Pakistan. Lahore: Vanguard.

Rahman, Tariq. 2001. "Language, Knowledge, and Inequality." In Linguistic Structure and Language Dynamics in South Asia: Papers from the proceedings of SALA XVIII roundtable. Anvita Abbi, R.S. Gupta, Ayesha Kidwai (eds.) 185-196. Delhi: Motilal Banarsidass.

Rahman, Tariq. 2002. "The Language of the Salariat." In The Post-Colonial State and Social Transformation in India and Pakistan. S. M. Naseem \& Khalid Nadvi (eds.) 97-128. Karachi: Oxford University Press.

Scherer, Klaus R. 1979. "Voice and Speech Correlates of Perceived Social Influence in Simulated Juries." In Language and Social Psychology. Howard Giles \& Robert N. St. Clair (eds.) 88120. Baltimore: University Park Press.

Schreuder, Robert \& Bert Weltens (eds.) 1993. The Bilingual Lexicon. Philadelphia: John Benjamin.

Seliger Herbert W. \& Robert M. Vago (eds.) 1991. First Language Attrition. New York: Cambridge University Press.

Sharma, Devi Datt. 1971. Syllabic Structure of Hindi and Panjabi. Chandigarh: Panjab University Publications Bureau.

Thomason, Sarah Grey \& Kaufman, Terrence. 1988. Language Contact, Creolization, and Genetic Linguistics. Berkeley, California.

Weinreich, Uriel. 1953. Languages in Contact. The Hague.

Weltens, Bert \& Marjon Grendel. 1993. “Attrition of Vocabulary Knowledge.” In The Bilingual Lexicon. Robert Schreuder \& Bert Weltens (eds.) 135-156. Philadelphia: John Benjamins. 